\title{
NESTING AND PARENTAL CARE IN CINNYRIS JUGULARIS
}

\author{
Swetaleena Mishra \\ Department of Zoology, \\ Kolhan University (Jharkhand)
}

\begin{abstract}
Building nests, laying eggs and parental care these are few of the characteristics that define the basic instinct of higher vertebrates for continuance of their life cycle on the earth. The nesting behavior and parental care is most profound and highly specialized in the mammals but these behaviors are very peculiar in other vertebrates as the nest types and parental care varies from species to species in the lower vertebrates. In this paper the nesting behavior and brood care of the yellow-bellied sunbird has been studied. These small birds are mostly territorial and found in pairs and both the parents take care of the brood and feed them till their offspring become independent and leave the nest.
\end{abstract}

Keywords - Brood, Sexual dimorphism, Monogamous, Eclipse plumage

\section{INTRODUCTION}

The olive-back sunbird is the most common species of sunbirds found in the southeast Asia. These birds are 9$11 \mathrm{~cm}$ long, the males being slightly larger in size. This species of sunbird exhibits amazing sexual dimorphism, the males being more attractive and intensely coloured. This sunbird is commonly referred to as 'yellow- bellied sunbird'.

This species is classified as

$\begin{array}{lll}\text { Phylum } & - & \text { Chordata } \\ \text { Class } & - & \text { Aves } \\ \text { Order } & - & \text { Passeriformes } \\ \text { Superfamily } & - & \text { Passeroidea } \\ \text { Family } & - & \text { Nectariniidae } \\ \text { Genus } & - & \text { Cinnyris } \\ \text { Species } & - & \text { jugularis }\end{array}$

The species identification of this bird was confirmed with the help of 'The Book of Indian Birds' by Salim Ali.

\section{MATERIALS AND METHODS}

2.1. Description of site- The study was carried out in the CRPF campus at Mosabani, Jharkhand. The place is surrounded by small mountains and is a forest division. Though, a residential area, it has very less population, the locales being mostly the tribal people. This place has a lot of greenery and Subarnarekha river flows nearby, just $3 \mathrm{kms}$ away. Due to the above cited factors, this place has a rich diversity of flora and fauna, especially immense richness of plants and birds is seen here.

2.2 Duration and time of research- The sunbirds constructed their nests at two different places in the house, once in the month of January and again in the month of June. So, this study was conducted during a span of three months on two different sunbird nests. The nest sites were left undisturbed. Besides, some precautions were taken so that the birds feel safe like fogging, smoke due to burning of dry leaves and wastes and loud noise was completely avoided near the nesting sites.

2.3 Location of nests- During February the female made nest suspended from an electric wire present at the roof of the house and in June, another female sunbird built a nest suspended from a cloth line in the house. The aim of the research is to study the nesting behaviour and parental care in the common garden olive-backed sunbird.

\section{RESULTS AND DISCUSSION}

During the study period of six months, the following traits of Cinnyris jugularis while nesting and brood care were observed and noted down carefully. The nest was closely observed three times a day and following observations were noted which are tabulated below.

\begin{tabular}{|c|c|c|}
\hline $\begin{array}{c}\text { Nesting } \\
\text { activity (Feb- } \\
\text { Mar) }\end{array}$ & Date (Feb-Mar) & Date (Jun-Jul) \\
\hline $\begin{array}{c}\text { 1. Nest } \\
\text { construction }\end{array}$ & $\begin{array}{c}\text { Started building } \\
\text { nest on 25-01-19 } \\
\text { and completed } \\
\text { on 01-02-19. }\end{array}$ & $\begin{array}{c}\text { Started building nest } \\
\text { on 06-06-19 and } \\
\text { completed } \\
\text { on 12-06-19. }\end{array}$ \\
\hline $\begin{array}{c}\text { 2.Egg laying } \\
\text { 3.Incubation } \\
\text { period }\end{array}$ & $\begin{array}{c}\text { First egg- 06-02-19 } \\
07-02-19\end{array}$ & $\begin{array}{c}\text { First egg- 19-06-19 } \\
\text { Second egg- } \\
20-05-19\end{array}$ \\
\hline $\begin{array}{c}\text { 4.Hatching of } \\
\text { eggs }\end{array}$ & $\begin{array}{c}11-02-19 \text { and } \\
13-02-19\end{array}$ & $\begin{array}{c}7 \text { days } \\
27-06-19\end{array}$ \\
\hline $\begin{array}{c}\text { 5.Aband } \text { and } \\
\text { nest }\end{array}$ & $02-03-19$ & $15-07-19$ \\
\hline
\end{tabular}




\section{International Journal of Engineering Applied Sciences and Technology, 2019 \\ Vol. 4, Issue 4, ISSN No. 2455-2143, Pages 119-122 \\ Published Online August 2019 in IJEAST (http://www.ijeast.com)}

- Construction of nest- The female bird solely constructs the nest with the help of soft grass, cobwebs, droppings, bits of papers, fibers and strings. The site for nesting is finalized by the female after reiki of 2-3 days and is constructed at a warm sunny place. Generally, the sunbirds construct their nest hanging from slender branches of shrubs or trees or thin electric or other wires at houses.

-Nest- The nest is oblong in shape and has an overhanging porch-like structure at the front below which a small entrance is present. While building the nest, first the female ties a long string that trails till the bottom end of the nest. The entire nest is made along this long hanging string. The female spreads its wings inside the nest to expand and adjust the size of the nest.

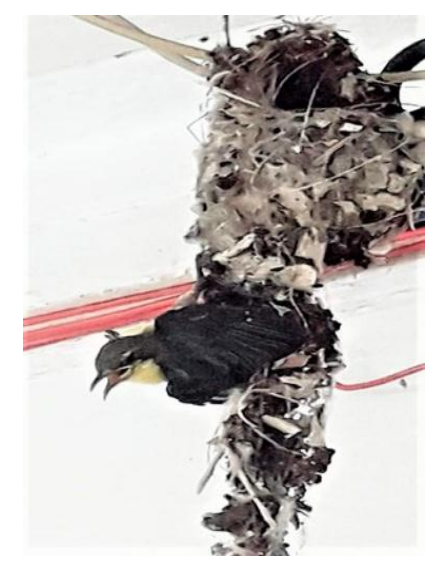

Fig.1: Chick attempting its first flight, from the $1^{\text {st }}$ nest hanging from an electric wire

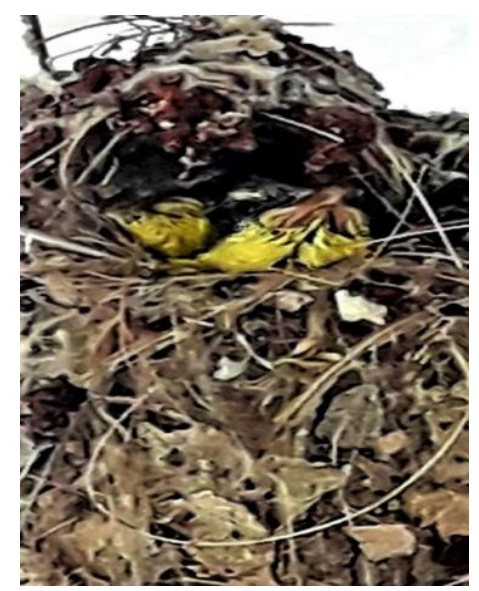

Fig.2: Chirping chicks

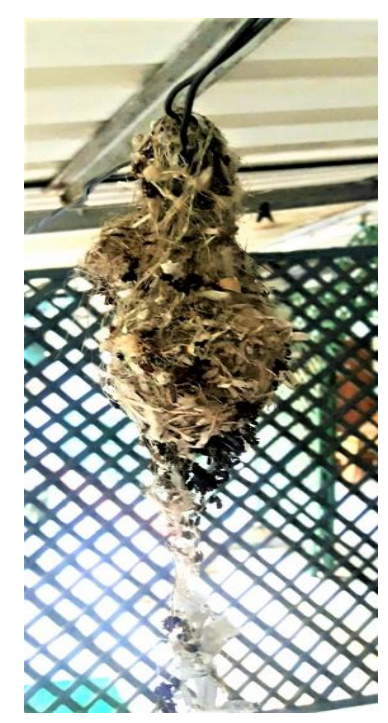

Fig. 3: $2^{\text {nd }}$ Nest hanging from cloth line

$\downarrow$ Eggs-The eggs are small and dark greyish in color. The brood consists of mostly two eggs.

Incubation-The female incubates the eggs for about a week. During this period the female often leaves the nest for short durations to nearby flowering shrubs for feeding nectar. The male bird stays in the nearby surroundings guarding the nest and brood. The male is more aggressive in nature.

Feeding- They mostly feed on nectar from flowers. They possess a comparatively long, thin and slightly curved bill pointing downwards. This structure of their bills facilitates their nectar-feeding trait. These birds are very tiny and light. They hover around the flowers and occasionally perch over them for sipping nectar. While they hover around the flowers, they very closely resemble the humming birds. Their tongue is peculiarly modified as a bristled and tubular form that assists in sucking nectar from various types of flowers in the surrounding. The sunbirds also feed upon small insects while rearing the chicks, may be for providing them with essential nutrients for their growth and development.
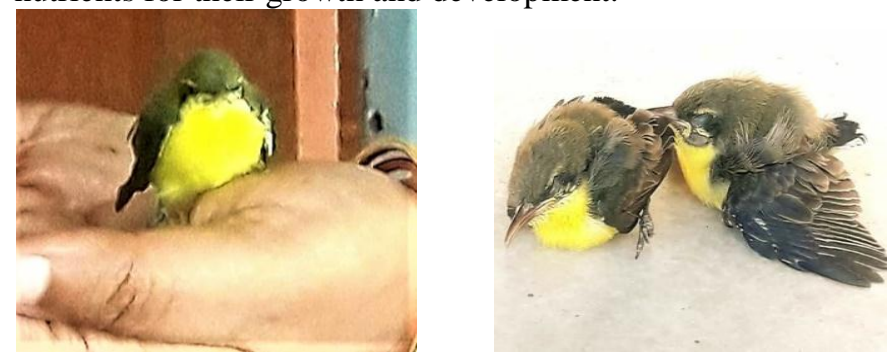

Fig.4: Chicks of Sunbird

It was observed during both periods of nesting that the female builds the nest and the male guards it. The female spends maximum time in the nest feeding and guarding the chicks and they also frequently remove the fecal sacs from the nest to keep it clean. Besides, the males also feed the young 


\section{International Journal of Engineering Applied Sciences and Technology, 2019 \\ Vol. 4, Issue 4, ISSN No. 2455-2143, Pages 119-122 \\ Published Online August 2019 in IJEAST (http://www.ijeast.com)}

chicks showing a peculiar biparental co-operation for brood care. This may be the reason that helps these sunbirds maintain a monogamous relationship. The parental care is shown by both male and female species. A very good example of biparental cooperation is seen in these sunbirds as both parents take care of their young ones even after they leave the nest and start living on trees and shrubs.
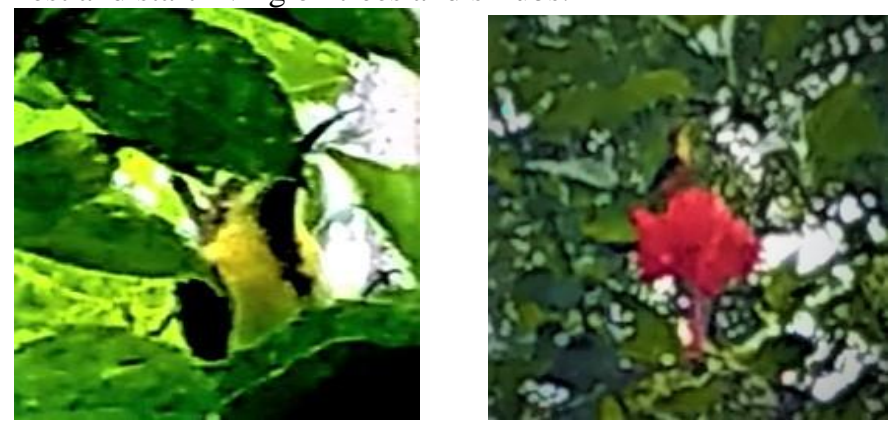

Fig.5: Eclipse male Sunbird

The plumage of male sunbird is almost same as that of the female bird but it has small dark patch on its collar and is bit darker than the female. This is called the eclipse plumage of male. The most peculiar fact about the plumage of male sunbird is that it shows metallic shine and becomes completely dark during the breading season.
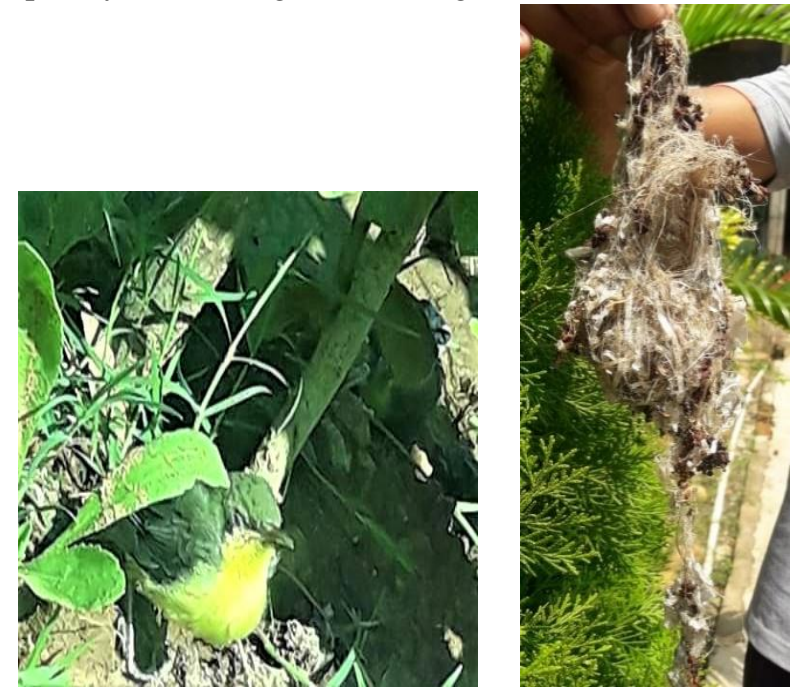

Fig.6: Young bird left nest and the abandoned nest

This sunbird produces very loud and pinching sound. This may the reason that these beautiful birds are not caged.

\section{CONCLUSION}

Sunbirds are a group of very small and brightlycoloured old-world birds. These are diurnal species. The sunbirds fly with very fast stokes of their small wings. The sunbirds are found in a wide range of habitats. They are found in grasslands, in woodlands, in forests and also show a great acquaintance with the humans. The sunbirds are often found in human proximity - in the gardens, agricultural fields and also in the plantation areas. Their closeness to human habitats may be due to the fact that most of the forests and grasslands are nowadays destroyed directly or indirectly by the human interference. Thus, due to their habitat loss and they try to survive and flourish within propinquity to the humans.

Various studies have suggested that these garden birds play a very significant role in the pollination of different types of bright colored flowers (Hargreaves, A.L., Johnson, S.D. and Nol, E., 2004). They also feed upon insects and caterpillars, thus, in a way, keep some pests away from the flowering plants. Therefore, we can say that apart from their exquisite nesting and parental care traits, these beautiful birds should also be studied for their immense ecological significance.

\section{REFERENCES}

1. Agostini, K., Shazima, M. \& Shazima, I. (2006). Bird pollination of explosive flowers while foraging for nectar and caterpillars, Biotropica 38, (Pg.674-678).

2. Ali, S. (1941). The Book of Indian Birds. Bombay Natural history Society.

3. Ali, S. and Ripley, S.D. (1999). Handbook of the birds of India and Pakistan. Oxford University Press $2^{\text {nd }}$ ed., Delhi.

4. Bhardwaj, G.S. \& Sangha, H.S. (2016). Nesting of Purplerumped Sunbird, Leptocoma zeylonica in southern Rajasthan, and its occurrence in the Thar Desert. Indian BIRDS 12 (1), (Pg.10-11).

5. Cheke, R.A., Mann, C.F. and Allen, R. (2001). Sunbirds: A Guide to the Sunbirds, Spiderhunters, flower peckers and Sugarbirds of the world. Helm, London, UK.

6. Craig, A. and Simon, C. (1991). Sunbird and Sugarbird seasons. Safring News 20, (Pg.9-12).

7. Cockburn, A. (2006). Prevalence of different modes of parental care in birds. Proceedings of the Royal Society Biological Sciences 273 (1592), (Pg.1375-1383).

8. Ghardiran, T., Qashqaei, A.T. and Dadras, M. (2007). Notes on Feeding and Breeding Habits of the Purple Sunbird Cinnyris asiatica in Bandar Addas, South Iran. Podoces 2 (2), (Pg.112-126).

9. Hargreaves, A.L., Johnson, S.D. \& Nol, E. (2004). Do floral syndromes predict specialization in plant pollination systems? An experimental test in an "ornithophilous" African Protea. Oecologia 140 (2), (Pg.295-301).

10. Irwin, M.P.S. (1995). The Plain-backed Sunbird in the Transvaal and Zimbabwe. Honeyguide 41, (Pg.26-27).

11. Moller, A.P. (2000). Male parental care, female reproductive success and extrapair paternity. Behavioural Ecology 11 (2), (Pg.161-168).

12. Pande, S., Sant, N. (2008). Olive-backed Sunbird Cinnyris juguaris nesting from electric wires in Great Nicobar Island. Indian Birds 4 (3), (Pg.116-117). 
13. Rand, A.L. (1953). Parental Care and its Evolution in Birds. The Wilson Bulletin 65 (3), (Pg.215-217).

14. Sheldon, B.C. (2002). Relating paternity to parental care. Philos. Trans. Royal Society of London Ser. B 357, (Pg.341350).

15. Sekercioglu, C.H., Wenny, D.G. and Whelan, C.J. (2016), Why Birds Matter: Avian Ecological Function and Ecosystem Services. University of Chicago Press.

16. Sohi, G.K. \& Kler, T.K. (2017). Adaptations of avian nesting behaviour in relation to indigenous trees and housing structures in Punjab. Journal of entomology and Zoological Studies 5 (5), (Pg.1045-1051).

17. Tayade, S.N., Dabhade, D.S. and Ukalkar, M.N. (2014). Nesting Behaviour of Purple Sunbird, Nectarinia asiatica. Journal of Global Biosciences 3, (Pg.1116-1119).

18. Wesley, H.D. (2004). A glimpse of the breeding biology of the Purple-rumped Sunbird, Nectarinia zeylonica (Linnaeus, 1766). Newsletter for Ornithologists 1(1-2), (Pg.9-10). 